\title{
Isolation, Molecular Characterization and Probiotic Potential of Lactic Acid Bacteria in Saudi Raw and Fermented Milk
}

\author{
Maged S. Bin Masalam, ${ }^{1}$ Ahmed Bahieldin, ${ }^{1}$ Mona G. Alharbi, ${ }^{1}$ Saad Al-Masaudi, \\ Soad K. Al-Jaouni, ${ }^{2}$ Steve M. Harakeh ${ }^{D},{ }^{3}$ and Rashad R. Al-Hindi ${ }^{1}$ \\ ${ }^{1}$ Department of Biology, Faculty of Science, King Abdulaziz University, Jeddah, Saudi Arabia \\ ${ }^{2}$ Department of Pediatric Hematology/Oncology, Yousef Abdullatif Jameel Chair of Prophetic Medicine Application, \\ King Abdulaziz University Hospital, Faculty of Medicine, KAU, Saudi Arabia \\ ${ }^{3}$ Special Infectious Agents Unit, King Fahd Medical Research Center, Yousef Abdullatif Jameel Chair of Prophetic Medicine Application, \\ KAU, Saudi Arabia
}

Correspondence should be addressed to Steve M. Harakeh; sharakeh@gmail.com

Received 28 December 2017; Revised 22 March 2018; Accepted 12 July 2018; Published 25 July 2018

Academic Editor: Mohammed S. Ali-Shtayeh

\begin{abstract}
Copyright (C) 2018 Maged S. Bin Masalam et al. This is an open access article distributed under the Creative Commons Attribution License, which permits unrestricted use, distribution, and reproduction in any medium, provided the original work is properly cited.

Probiotic bacteria can confer health benefits to the human gastrointestinal tract. Lactic acid bacteria (LAB) are candidate probiotic bacteria that are widely distributed in nature and can be used in the food industry. The objective of this study is to isolate and characterize LAB present in raw and fermented milk in Saudi Arabia. Ninety-three suspected LAB were isolated from thirteen different types of raw and fermented milk from indigenous animals in Saudi Arabia. The identification of forty-six selected LAB strains and their genetic relatedness was performed based on $16 \mathrm{~S}$ rDNA gene sequence comparisons. None of the strains exhibited resistance to clinically relevant antibiotics or had any undesirable hemolytic activity, but they differed in their other probiotic characteristics, that is, tolerance to acidic $\mathrm{pH}$, resistance to bile, and antibacterial activity. In conclusion, the isolates Lactobacillus casei MSJ1, Lactobacillus casei Dwan5, Lactobacillus plantarum EyLan2, and Enterococcus faecium Gail-BawZir8 are most likely the best with probiotic potentials. We speculate that studying the synergistic effects of bacterial combinations might result in a more effective probiotic potential. We suspect that raw and fermented milk products from animals in Saudi Arabia, especially Laban made from camel milk, are rich in LAB and have promising probiotic potential.
\end{abstract}

\section{Introduction}

Probiotic bacteria can confer health benefits to the human gastrointestinal tract [1-3]. Lactic acid bacteria (LAB) are candidate probiotic bacteria [4] that are widely distributed in nature and can be used in the food industry [5]. LAB are a group of microaerophilic or anaerobic Gram-positive bacteria that are unable to form spores or produce catalase and are characterized by the absence of the cytochrome system $[6,7]$ and the ability to produce antimicrobials for biopreservation $[8,9]$. Certain foods, including dairy products, for example, yogurt, are considered good sources of probiotics [10]. The majority of microbiota in raw milk and fermented milk products include the genera Lactobacillus, Enterococcus, Lactococcus, Leuconostoc, Pediococcus, Oenococcus, Carnobacterium,
Streptococcus, and Weissella [11-13]. The most obvious benefits of LAB fermentation include increased food palatability and improved shelf life [14]. LAB are generally recognized as safe (GRAS) because they are able to produce bacteriocins and their consumption confers several health benefits, such as controlling intestinal infections, improving lactose utilization, lowering blood ammonia levels, providing efficient resistance against gastric acid and bile [11, 15-19], influencing the immune system, and lowering serum cholesterol levels $[20,21]$. LAB also adhere to the gastrointestinal tract and confer pathogen inhibition [11, 22, 23]. Interestingly, the presence of $\mathrm{LAB}$ resulted in no change or small changes in the abundance of other intestinal microbial groups [24].

DNA-based molecular identification of the 16S rRNA gene can discriminate between closely related bacterial 
species [25-29]. Amplified ribosomal DNA restriction analysis (ARDRA) and randomly amplified polymorphic DNA (RAPD) were successfully used in discriminating LAB [30, 31]. The approaches include PCR-RFLP followed by direct sequencing of the $16 \mathrm{~S}$ rDNA gene and a BLAST search against the sequences of other organisms that are available at the National Center for Biotechnology Information (NCBI) [32].

The isolation, identification, and characterization of novel LAB strains have two benefits. The first is to reveal the characteristic taxonomy of the LAB and the second is to obtain promising beneficial and functional probiotic LAB $[33,34]$. There is little research regarding the isolation and characterization of LAB from dairy products. Therefore, the aim of the present work was to isolate and to identify, at the molecular level, the lactic acid bacteria contained in raw milk and fermented milk which were produced indigenously in Saudi Arabia. These LAB were evaluated for their functional traits, probiotic properties, and ability to inhibit the growth of pathogenic and food poisoning bacteria.

\section{Materials and Methods}

2.1. Samples and Media. Thirteen $(0.5 \mathrm{~kg})$ samples of raw milk and traditional fermented milk from indigenous animals procured in Jeddah Province, Saudi Arabia, were used in this study. These samples were collected from the local market and were stored in a fridge until use. MRS agar and MRS broth media (Oxoid ${ }^{T M}$, Thermo Fisher Scientific, USA) were used to isolate and support the growth of LAB and to inhibit the growth of unwanted bacteria [35]. MRS agar and broth were also used to enumerate the LAB. M17 agar and M17 broth (Oxoid, Thermo Fisher Scientific, USA) were used for isolating the streptococci in dairy products $[36,37]$. Blood agar (Oxoid, Thermo Fisher Scientific, USA) and MullerHinton agar media (MHA) (HiMedia, India) were used to evaluate hemolytic activity and antimicrobial activity of the $\mathrm{LAB}$, respectively.

2.2. Isolation of $L A B$ and Maintenance Method. $50 \mathrm{~g}$ of the samples was placed into sterile stomacher bags and then were diluted (1:10) with MRS broth, processed to enrich the LAB by stomaching, sealed, and incubated overnight at $30^{\circ} \mathrm{C}$ [38]. Lactic acid bacteria were isolated by 5 -fold serial dilutions. At the beginning, $1 \mathrm{~mL}$ of sample stomachate was added to $9 \mathrm{~mL}$ of sterile physiological water $(0.85 \% \mathrm{NaCl})$ and was further serially diluted. Then, $0.1 \mathrm{~mL}$ aliquots of the samples' suitable dilutions were plated onto MRS agar and M17 agar. The plates were incubated at $37^{\circ} \mathrm{C}$ for $24-48 \mathrm{~h}$ in anaerobic jars using the AnaeroGen ${ }^{\mathrm{TM}}$ anaerobic system (Oxoid, Thermo Fisher Scientific, USA) [25, 39, 40] and in microaerobic conditions $\left(5 \% \mathrm{CO}_{2}\right)$ [41]. MRS agar plates were used to enumerate the initial growth of the LAB in each sample [25]. All experiments were performed in triplicate. The resulting isolates were randomly selected from the medium surface and were streaked twice on fresh MRS to be purified [35]. The isolated strains were maintained by culturing them in MRS broth medium at $30^{\circ} \mathrm{C}$ and then storing at $-80^{\circ} \mathrm{C}$ in MRS broth containing 50\% (v/v) glycerol. MRS broth and M17 broth were used in all subsequent experiments [42, 43].
Isolates from the stocks were subcultured in MRS broth for further studies.

2.3. Phenotypic and Genotypic Identifications. For all of the isolated strains, the colony morphology on MRS solid medium and M17 agar was determined visually and their motility was recorded using the hanging drop technique. Gram staining was performed to determine the cell morphology and Gram stain reaction of the isolates. Catalase and cytochrome oxidase tests were also performed $[39,42]$. As for genotypic identification, cell pellets were harvested from $2 \mathrm{~mL}$ of overnight cultures (up to $2 \times$ $10^{9}$ bacterial cells) of LAB grown in MRS broth by centrifugation for $10 \mathrm{~min}$ at $5,000 \times \mathrm{g}$, and the supernatant was discarded. Then, DNA extraction was done using a GeneJET Genomic DNA Purification Kit (cat. no. K0721, Thermo Fisher Scientific, Waltham, MA, USA) following the manufacturer's instructions. PCR was carried out and the universal primers were designed and synthesized (Medicbiotrade, Germany) to amplify nearly the entire region of the 16S rDNA gene; the primers were 16S:F27 (forward: $5^{\prime}$ AGAGTTTGATCCTGGCTCAG-3') and 16S:R27 (reverse: $5^{\prime}$-AAGGAGGTGATCCAGCCGCA- $\left.3^{\prime}\right)$. The primers were designed to amplify the $16 \mathrm{~S}$ rDNA gene ( 1.6 kb, [44]) with GC contents of $50-60 \%$ for a higher melting temperature (Tm) to avoid nonspecific amplification [39]. PCR conditions were one cycle of $5 \mathrm{~min}$ of initial denaturation at $95^{\circ} \mathrm{C}$, followed by 35 cycles of amplification. Each cycle consisted of denaturation at $95^{\circ} \mathrm{C}$ for $30 \mathrm{sec}$, annealing at $58^{\circ} \mathrm{C}$ for $30 \mathrm{sec}$, and extension at $72^{\circ} \mathrm{C}$ for $1 \mathrm{~min}$. The last cycle was $10 \mathrm{~min}$ at $72^{\circ} \mathrm{C}$ as a postextension step. Electrophoresis in $0.5 \mathrm{x}$ TBE buffer was conducted on an $0.8 \%$ agarose gel for the amplicons with a $1 \mathrm{~kb}$ DNA standard (TrackIt, Invitrogen, Waltham, MA, USA), and the gels were stained with ethidium bromide and photographed. The amplicons were purified, they were sequenced for the $16 \mathrm{~S}$ gene at Macrogen Inc. (Seoul, Korea), and they were BLASTsearched to detect similar sequences in the NCBI database (https://www.ncbi.nlm.nih.gov) using the Discovery Studio Gene v1.5 (DSGene v1.5) program [32, 42]. A fragment of $\sim 1000 \mathrm{nt}$ involving five variable $(\mathrm{V})$ regions was further utilized. Binary data metrics were entered into TFPGA (version 1.3) and were analyzed using a qualitative route to generate a similarity coefficient. The dissimilarity coefficients were used to construct dendrograms by the sequential hierarchical and nested clustering (neighbor joining (NJ)) method with NTSYSpc (version 2.10, Exeter Software).

2.4. Antibiotic Susceptibility, Hemolytic Activity, and Acid Bile Tolerance. The antibiotic susceptibility of the identified LAB was determined by using the agar disk diffusion method [45]. Fifteen antibiotics (Oxoid, Thermo Fisher Scientific, USA) were selected as representatives of the different classes of clinically important antibiotics. Inoculates $\left(10^{6}\right.$ CFU mL $\mathrm{m}^{-1}$ ) of the $\mathrm{LAB}$ were swabbed onto the surfaces of Muller-Hinton agar plates and, then, the disks of antibiotics (amoxicillin/25 $\mu \mathrm{g}$, penicillin G/10 units, ceftriaxone/ $30 \mu \mathrm{g}$, cefoxitin $/ 30 \mu \mathrm{g}$, tobramycin $/ 10 \mu \mathrm{g}$, oxacillin $/ 1 \mu \mathrm{g}$, bacitracin/10 units, chloramphenicol $/ 30 \mu \mathrm{g}$, polymyxin $\mathrm{B} / 300$ 
units, gentamycin $/ 10 \mu \mathrm{g}$, neomycin $/ 30 \mu \mathrm{g}$, clindamycin $/ 2 \mu \mathrm{g}$, vancomycin $/ 256 \mu \mathrm{g}$, nitrofurantoin $/ 300 \mu \mathrm{g}$, and nalidixic acid $/ 30 \mu \mathrm{g}$ ) were applied onto the surface of the plates and incubated at $37^{\circ} \mathrm{C}$ and $5 \% \mathrm{CO}_{2}$ for $24 \mathrm{~h}[17,46]$. The plates were examined for the presence of inhibition zones around the antibiotic disks [43]. The inhibitory effect of the antibiotics was expressed as the diameter $(\mathrm{mm})$ of the inhibition zones.

Bacterial cells were grown on Columbia blood agar (Oxoid, Thermo Fisher Scientific, USA), supplemented with $5 \%(\mathrm{v} / \mathrm{v}$ ) human blood (obtained from King Abdulaziz University Hospital, Jeddah, KSA) to determine their ability to produce different types of hemolysins. Plates were incubated at $37^{\circ} \mathrm{C}$ in anaerobic jars (Oxoid, Thermo Fisher Scientific, USA) with gas-generating kits. After 24-hour and 72-hour incubation periods, the results were recorded. A clear zone on the blood agar plates was considered a positive result [42].

Tolerance of the LAB to acid and bile was determined as described [47]. All strains were grown at $37^{\circ} \mathrm{C}$ for $24 \mathrm{~h}$ in MRS broth and were suspended to an approximate cell concentra-

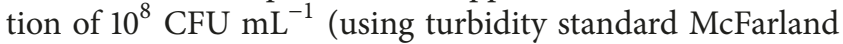
0.5 ) in MRS broth adjusted to $\mathrm{pH} 3.0$ for $2 \mathrm{~h}$, and the cells were then incubated in $0.5 \%$ w/v bile (Sigma-Aldrich, France) for $4 \mathrm{~h}$. These conditions were chosen to represent the time required for the bacteria to pass through the gastrointestinal system and the $\mathrm{pH}$ value and bile concentration found in the stomach and intestine, respectively. Bacterial viability was assessed by enumeration on MRS agar plates at zero time and at the end of incubation.

\subsection{Evaluation of Antibacterial Activity of Identified Strains.} The agar well diffusion method was used to adequately investigate the antibacterial potential of the 46 identified LAB as described by Schillinger et al. (1996), Chahad et al. (2012), and Messaoudi et al. (2012a). Suspensions of seven indicator bacterial cultures, namely, Staphylococcus aureus ATCC 25923, methicillin-resistant Staphylococcus aureus (MRSA) ATCC 43330, Escherichia coli ATCC 25922, Salmonella spp., Shigella sonnei ATCC 25931, Enterococcus faecalis ATCC 29212, and Listeria monocytogenes ATCC 13932, provided by the Microbiology Laboratory of King Abdulaziz University Hospital, Jeddah, KSA, were prepared using turbidity standard McFarland 0.5. Then, $150 \mu \mathrm{L}$ of these suspensions was inoculated onto MHA medium by the streaking plate method, and four wells were punched in each inoculated agar medium plate using a sterile cork borer ( $6 \mathrm{~mm}$ diameter). Cell-free supernatant (CFS) of LAB grown in MRS was prepared by centrifugation at $10,000 \times \mathrm{g}$ for $20 \mathrm{~min}$ and $4^{\circ} \mathrm{C}$. Then, $100 \mu \mathrm{L}$ aliquots of the CFS of each strain were pipetted into their designated wells on the plates. Finally, the susceptibility of the test organisms against MRS broth was taken as a control. All inoculated plates were incubated at $37^{\circ} \mathrm{C}$ for $18-24 \mathrm{~h}$. After incubation, the diameter of each formed inhibition zone was measured twice using ruler; then, the average was taken to represent the antibacterial activity.

2.6. Statistical Analysis. Data were expressed as the mean \pm standard deviation (SD) calculated over independent experiments performed in triplicate. For inference statistics,

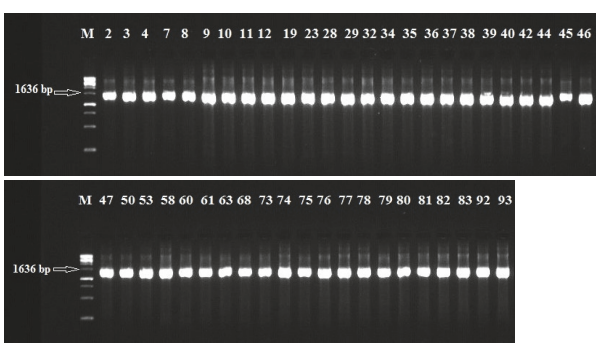

FIGURE 1: PCR amplification of the $16 \mathrm{~S}$ rDNA from the isolated LAB on $0.8 \%$ agarose gel. M: $1 \mathrm{~kb}$ DNA marker (TrackIt, Invitrogen). Numbers 2-4, 7-12, 19, 23, 28, 29, 32, 34-40, 42, 44-47, 50, 53, 58, 60, $61,63,68,73-83,92$, and 93 refer to the strains numbers in Table 1.

one-way analysis of variance (ANOVA) was applied, and it was performed with the Statistical Package for the Social Sciences (SPSS/PC, version 20.0).

\section{Results}

3.1. Isolation and Characterization of $L A B$. A total of 93 lactic acid bacteria (LAB) were isolated from the 13 collected samples of locally produced raw milk and fermented milk, such as fresh raw milk, frozen raw milk, fresh cheese, salty cheese, cooked cheese, stirred yogurt (Laban), qeshta (cream), madheer (dried fermented milk), yogurt, and butter. These samples originated from different animal sources, including cows, goats, and camels. The LAB counts under microaerobic incubation conditions were higher than those under anaerobic conditions. For example, the mean counts (per gram of sample) in the samples of qeshta made of cow milk and stirred yogurt "Laban" made of camel milk grown for $48 \mathrm{~h}$ under microaerobic incubation conditions were between $4.1 \times 10^{6} \pm 0.2 \times 10^{6}$ and $2.2 \times 10^{10} \pm 0.2 \times$ $10^{10} \mathrm{CFU} \mathrm{g}^{-1}$, respectively, while these counts were between $4.7 \times 10^{2} \pm 0.6 \times 10^{2}$ and $2.7 \times 10^{10} \pm 0.3 \times 10^{9} \mathrm{CFU} \mathrm{g}^{-1}$, respectively, under anaerobic incubation conditions.

The colony morphologies of the isolates were visually observed on the surface of MRS solid medium; the color varied from white to pale creamy, the shape was circular, and the size ranged from 0.5 to $4 \mathrm{~mm}$ in diameter. Most strains (92.47\%) were Gram-positive. The isolated strains differed in their catalase and cytochrome oxidase activity, where $71 \%$ were negative for catalase activity and $72 \%$ were negative for cytochrome oxidase production activity. The motility of the isolated strains also differed when tested by the hanging drop technique, with $96 \%$ of the isolates being nonmotile.

The $16 \mathrm{~S}$ rDNA gene $(\sim 1.6 \mathrm{~kb})$ was amplified from all of the isolated strains (Figure 1). Then, the amplicons were columnpurified and sequenced. The resultant nucleotide sequences were BLAST-searched for homology with known sequences in the NCBI database. The results in Table 1 indicated that the nucleotide sequences of 46 strains aligned with the $16 \mathrm{~S}$ rDNA sequences of 14 different species belonging to five genera, namely, Enterococcus, Lactococcus, Lactobacillus, Streptococcus, and Weissella (Figure 2). These strains showed identities of $99 \%$ (12 strains), 98\% (14 strains), 97\% (12 strains), $96 \%$ (6 strains), and 95\% (2 strains). Analysis of the 


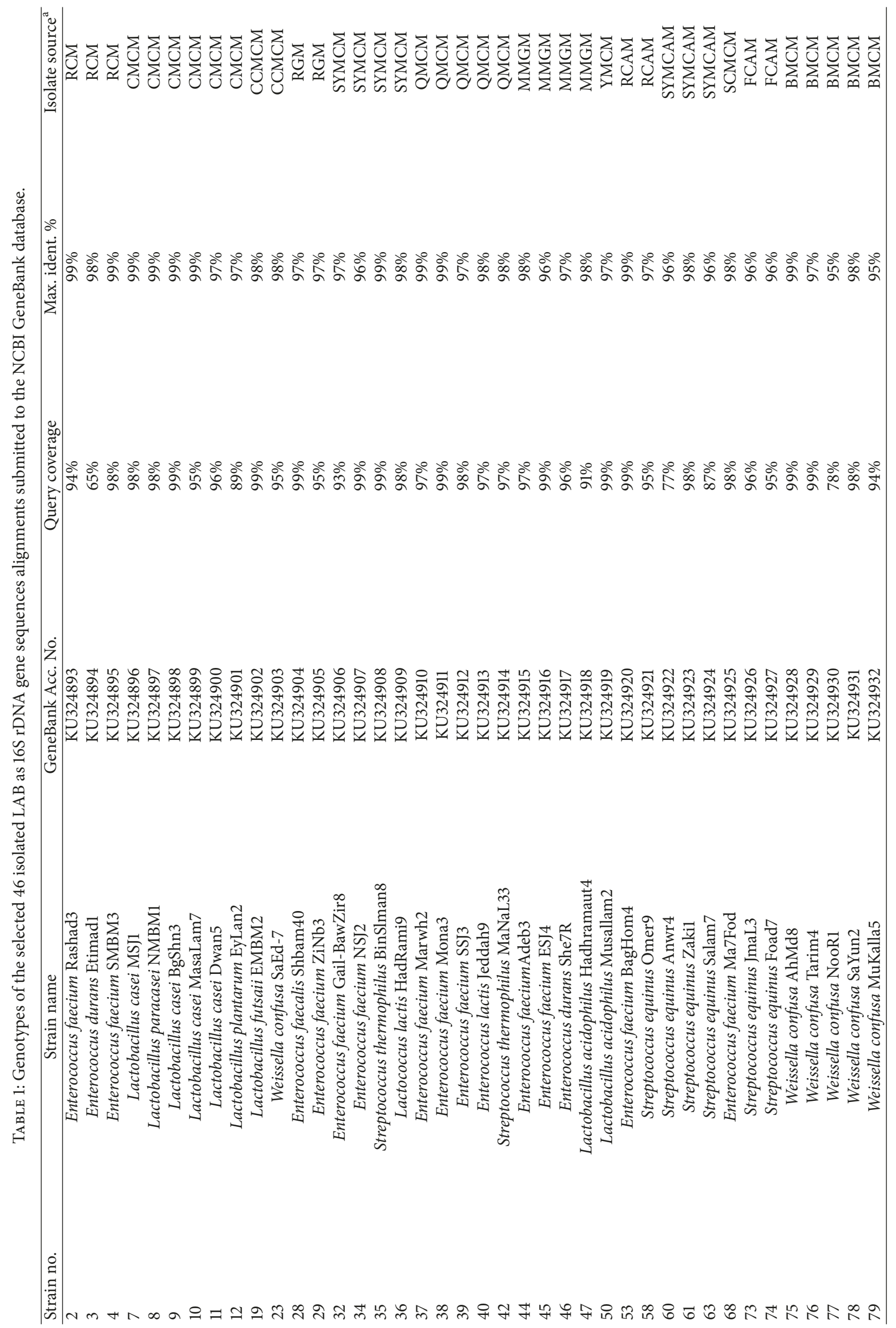




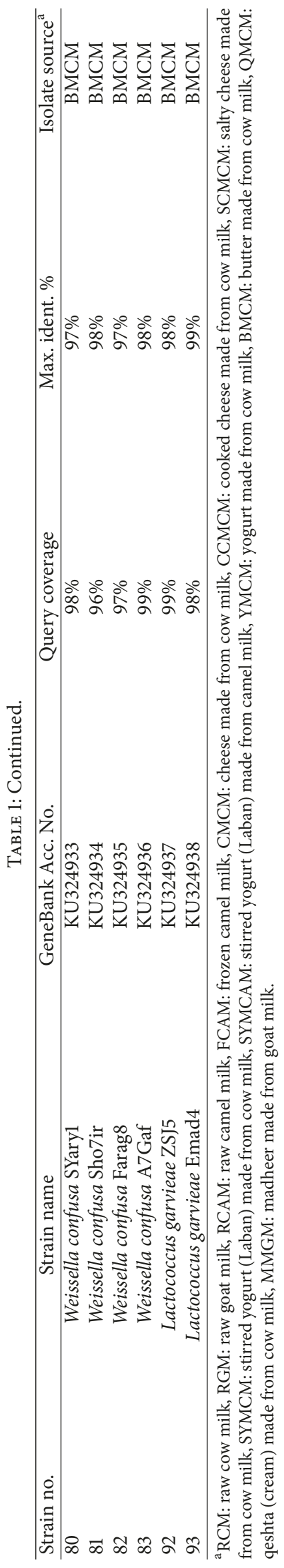




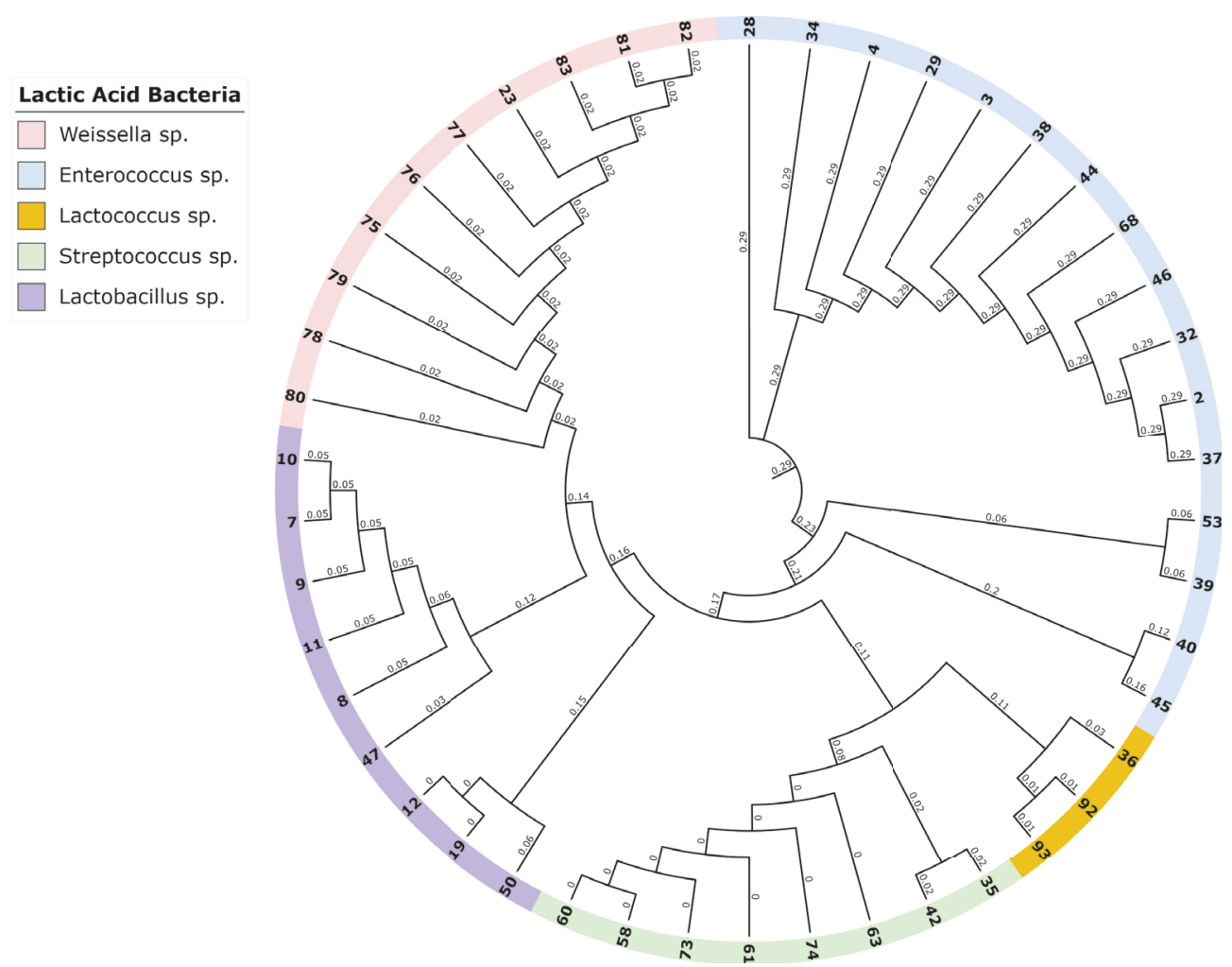

FIGURe 2: Phylogenetic neighbor joining (NJ) tree based on the $16 \mathrm{~S}$ rDNA full-length sequences $(\sim 1.6 \mathrm{~kb})$ of the $46 \mathrm{selected} \mathrm{LAB}$ strains of raw milk and fermented milk samples based on the results of sequence alignment. The numbers on the tree refer to the LAB strains in Table 1.

16 strains aligned with the genus Enterococcus indicated that 12 strains (i.e., Rashad3, SMBM3, ZiNb3, Gail-BawZir8, NSJ2, Marwh2, Mona3, SSJ3, Adeb3, ESJ4, BagHom4, and Ma7Fod) might belong to the species E. faecium, while two strains (i.e., Etimadl and She7R), one strain (i.e., Jeddah9), and one strain (i.e., Shbam40) might belong to the species E. durans, L. lactis, and E. faecalis, respectively. In studying the three strains of the genus Lactococcus, the results indicated that one strain (i.e., HadRami9) might belong to the species L. lactis, while two strains (i.e., Emad4 and ZSJ5) might belong to the species L. garvieae. Analysis of the nine strains of the genus Lactobacillus indicated that two strains (i.e., Hadhramaut4 and Musallam2), four strains (i.e., MSJ1, BgShn3, MasaLam7, and Dwan5), one strain (i.e., NMBM1), one strain (i.e., EyLan2), and one strain (i.e., EMBM2) might belong to the species L. acidophilus, L. casei, L. paracasei, L. plantarum, and $L$. futsaii, respectively. Two out of the eight strains of the genus Streptococcus (i.e., BinSlman 8 and MaNaL33) might belong to the species $S$. thermophilus, while the rest (i.e., Omer9, Anwr4, Zakil, Salam7, JmaL3, and Foad7) might belong to the species $S$. equinus. In addition, all ten strains of the genus Weissella (i.e., SaEd-7, AhMd8, Tarim4, NooR1, SaYun2, MuKalla5, SYary1, Sho7ir, Farag8, and A7Gaf) might belong to the species W. confusa.

\subsection{Susceptibility of LAB to Antibiotics and Hemolytic Activity.}

The tested $46 \mathrm{LAB}$ underwent an antibiotic susceptibility testing, and their growth was inhibited, to some extent, by the majority of the 15 tested antibiotics (Table 2). Interestingly, three antibiotics (bacitracin, gentamicin, and neomycin) had a great $(\sim 100 \%)$ inhibition effect against all the tested strains with a spectrum of inhibition zones of $14.0 \pm 0.0$ - $28.5 \pm 0.71,9.5 \pm 0.71-40.0 \pm 0.0$, and $9.5 \pm 0.71-$ $31.5 \pm 0.71 \mathrm{~mm}$, respectively. On the other hand, penicillin $\mathrm{G}$, tobramycin, and vancomycin inhibited the growth with a spectrum of inhibition zones of $15.0 \pm 1.41-40.0 \pm 1.41$, $11.0 \pm 1.41-23.5 \pm 0.71$, and $9.5 \pm 0.71-23.5 \pm 0.71 \mathrm{~mm}$ at lower levels of $89 \%, 73.9$, and $67.4 \%$ inhibition effect on the tested strains, respectively. There were only four antibiotics (i.e., nalidixic acid, polymyxin $\mathrm{B}$, oxacillin, and cefoxitin) that had low inhibition action at levels of $17.4 \%, 30.4 \%$, $34.8 \%$, and $45.7 \%$, respectively. The actions of the antibiotics oxacillin, cefoxitin, and nalidixic acid were resisted by many strains of lactobacilli and $W$. confusa. Five strains (namely, S. thermophilus BinSlman8, S. thermophilus MaNaL33, S. equinus Omer9, S. equinus JmaL3, and S. equinus Foad7) were resistant to penicillin $\mathrm{G}$, while 15 strains (32.6\%) were resistant to vancomycin. These strains belong to $L$. casei ( 4 strains), L. paracasei NMBM1, L. plantarum EyLan2, L. futsaii EMBM2, and $W$. confusa (8 strains).

In our study, $32(69.57 \%)$ of the tested strains were nonhemolytic ( $\gamma$-hemolysis), while the remaining 14 (30.43\%) strains exhibited $\alpha$-hemolytic activity, and these were $S$. thermophilus BinSlman8, S. thermophilus MaNaL33, W. confusa SaEd-7, W. confusa AhMd8, W. confusa Tarim4, W. confusa NooR1, W. confusa SaYun2, W. confusa MuKalla5, W. confusa Sho7ir, W. confusa Farag8, W. confusa A7Gaf, W. confusa SYary1, L. garvieae ZSJ5, and L. garvieae Emad4 (Table 2). 
苋

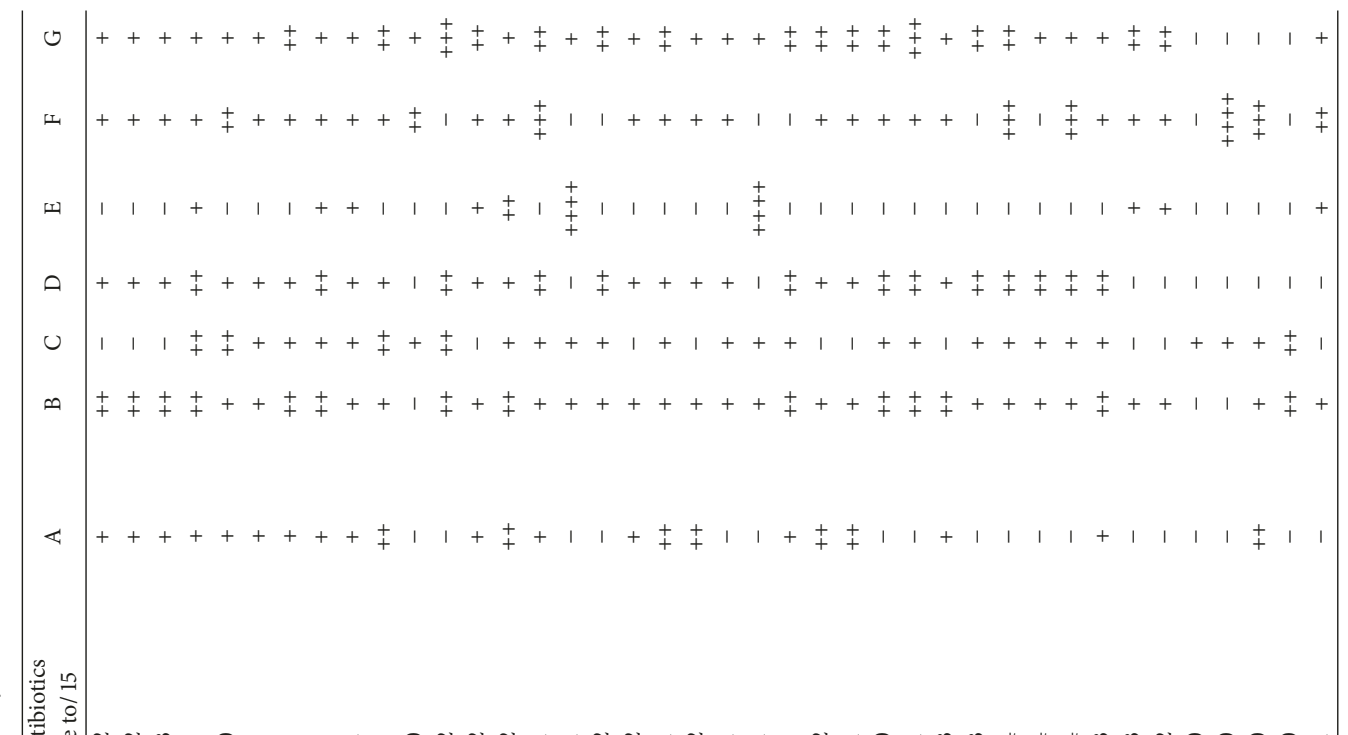

ปิ

穷安富

$\Xi \frac{1}{3}$

के है

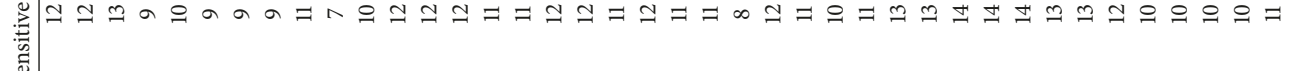

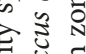

炡

क्षै

压芒

त्च

g ते

艺

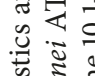

离密

㻤

䓀

के

i

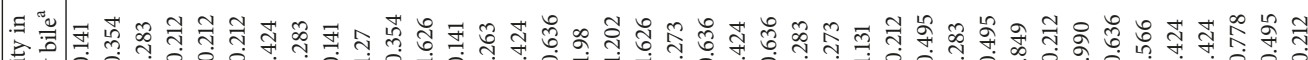

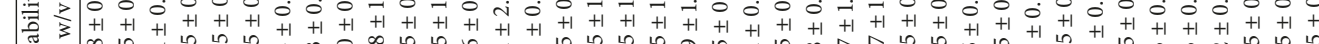

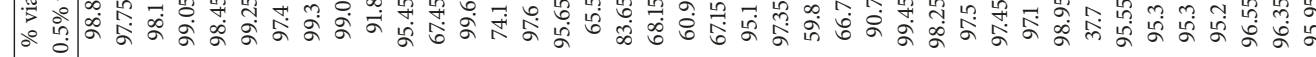
空。

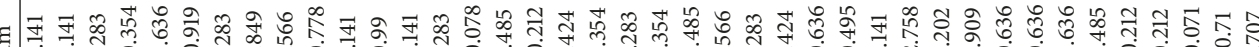

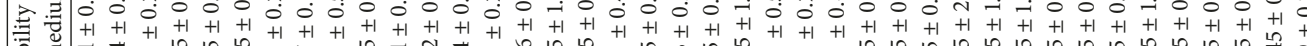

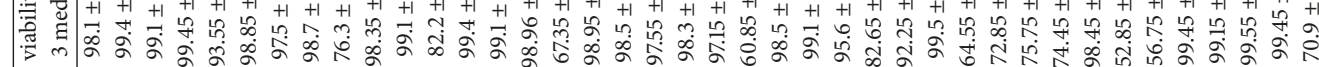

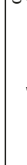

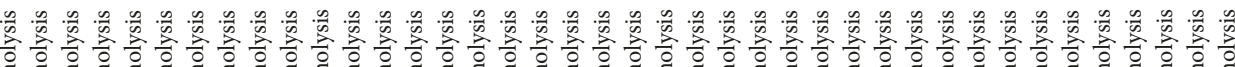

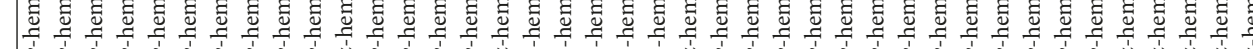

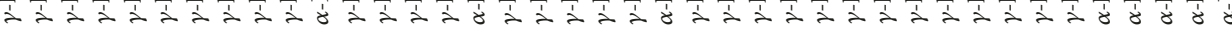

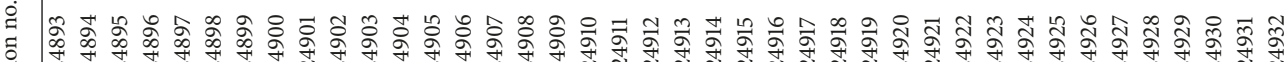

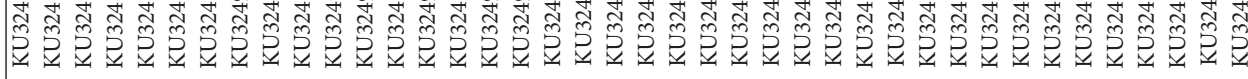

है के

: 


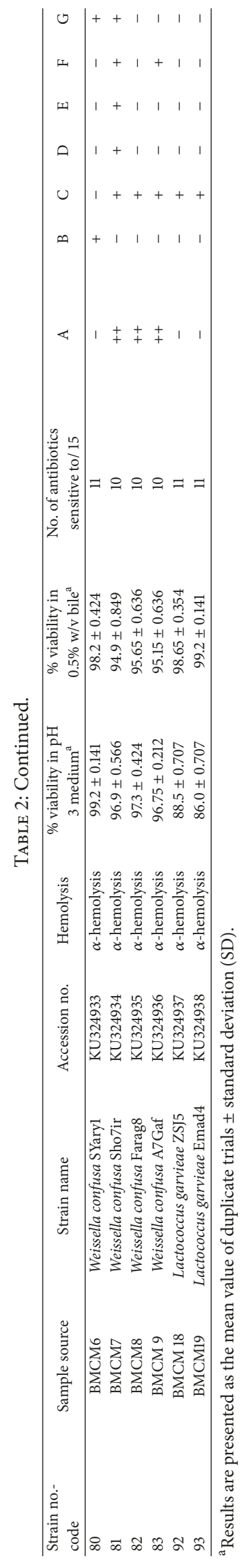




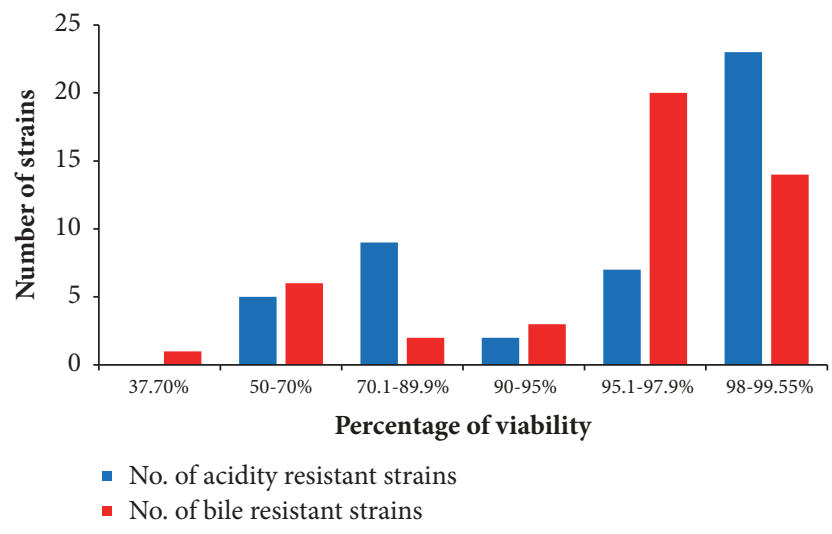

FIGURE 3: The percentage viability of the 46 LAB grouped according to their acidity and bile tolerance.

3.3. Acid and Bile Tolerance. The results showed that the 46 tested strains tolerated the acidic condition by variable ratios. The percentage viability of $50-70 \%, 70.1-89.9 \%, 90-$ $95 \%, 95.1-97.9 \%$, and $98-99.55 \%$ occurred among 5, 9, 2, 7 , and 23 strains, respectively (Table 2 and Figure 3). The most acid-tolerant strains were enterococci, such as $E$. faecium SMBM3,BagHom4, ZiNb3, Gail-BawZir8, ESJ4, NSJ2, Marwh2, SSJ3, Etimad1, and other LAB genera, such as $W$. confusa SaEd-7, AhMd8, Tarim4, NooR1, SaYun2, SYary1, L. casei MSJ1, BgShn3, Dwan5, L. futsaii EMBM2, and L. lactis HadRami9 (Table 2). The 46 LAB with acidity tolerances ranging from $52.85 \%$ to $99.55 \%$ were further tested for $4 \mathrm{~h}$ for $0.5 \% \mathrm{w} / \mathrm{v}$ bile tolerance. The obtained results showed that the survival percentages were $37.7 \%$, 50-70\%, 70.1-89.9\%, 90$95 \%, 95.1-97.9 \%$, and $98-99.55 \%$ for $1,6,2,3,20$, and 14 strains, respectively (Table 2 and Figure 3). A total of $71.7 \%$ of the strains were bile-tolerant without any significant loss of viability ( $>95 \%$ survival). The most bile-tolerant strains were among enterococci, such as E. faecium $\mathrm{ZiNb3}$, E. faecium Rashad3, and E. faecium SMBM3, and other species, such as L. casei BgShn3, L. casei Dwan5, L. casei MSJ1, L. plantarum EyLan2, L. acidophilus Musallam2, L. paracasei NMBM1, S. equinus Salam7, L. garvieae Emad4, L. garvieae ZSJ5, and W. confusa SYaryl (Table 2).

3.4. Antibacterial Activity of Isolated $L A B$. Spectra of the antibacterial activity of the CFS preparations for the $46 \mathrm{LAB}$ against seven bacterial indicator strains (4 Gram-positive and 3 Gram-negative) are shown in Table 2. There were variable spectra of inhibition zones of the antibacterial activity of the identified strains against the indicator bacteria which ranged from 8 to $30 \mathrm{~mm}$ in diameter. The results indicated antibacterial activity of the CFS of 25 (54.35\%), 38 (82.61\%), 33 (71.72\%), 31 (67.39\%), 11 (23.91\%), 33 (71.72\%), and $38(82.61 \%)$ LAB strains against E. faecalis, E. coli, Salmonella spp., Shigella sonnei, S. aureus, MRSA, and Listeria monocytogenes, respectively. L. casei MSJ1, L. casei Dwan5, L. plantarum EyLan2, and E. faecium Gail-BawZir8 strains showed antibacterial activity against all indicator bacteria at the different recorded spectra of inhibition. $20-30 \mathrm{~mm}$ zones of inhibition activity were noticed for S. thermophilus
BinSlman8 and S. thermophilus MaNaL33 against S. aureus and for $W$. confusa Tarim4 against MRSA. 15.1-20 mm zones of inhibition were recorded for E. faecium NSJ2, S. equinus Anwr4, S. equinus Salam7, and W. confusa NooR1 against MRSA and for E. faecalis Shbam40 and L. acidophilus Musallam2 against Listeria monocytogenes.

\section{Discussion}

Identified strains (68\%) were Gram-positive, catalasenegative, and oxidase- and hemolysis-producing, as well as chain-forming fermentative cocci and rods. These conclusions meet those reached earlier $[9,48]$ in the study on milk-grown LAB. Our pilot study aimed at the identification of LAB isolated from different types of dairy-based foods obtained from various animals in order to have a complete picture of the $\mathrm{LAB}$ found in those products. The results confirmed that the distribution of the isolated $L A B$ is sample-dependent. Enterococci were recovered from qeshta, madheer, raw cow milk, and raw goat milk. Lactobacilli were isolated from cheese and yogurt made from cow milk. Streptococci were abundant in stirred yogurt (Laban) made from camel milk and in frozen camel milk, and Weissella were isolated from butter made from cow milk. A phylogenetic tree was successfully generated from the multiple sequence alignment of full- and partial-length $16 \mathrm{~S}$ rDNA sequences of the 46 strains. We speculate that the LAB of the different genera can be positively discriminated using only the hypervariable region V2. Our data was aligned with that generated by Balcázar et al. [49] who indicated that the sequence containing both the $\mathrm{V} 1$ and $\mathrm{V} 2$ regions completely discriminated among LAB strains. Chakravorty et al. [50] also indicated that the V1, V3, V5, V6, and V7 regions are conserved, while the $\mathrm{V} 2, \mathrm{~V} 4, \mathrm{~V} 8$, and $\mathrm{V} 9$ regions are hypervariable in the family.

The antibiotic resistance of probiotic LAB is a controversial subject, as they may be reservoirs of antibiotic genes. The safety of LAB regarding food applications was evaluated by screening for the presence of virulence factors coding genetic determinants and by testing their phenotypic resistance to different antibiotics [51]. It is believed that the bacteria present in the intestinal microflora of foodproducing animals may acquire antibiotic resistance. Then, by the exchange of genetic material, the antibiotic-resistant bacteria can transfer the resistance factor to other pathogenic bacteria $[33,52]$. To resolve this problem in probiotic studies, it is necessary to certify that a prospective probiotic strain contains no transferable resistance genes. The 15 tested antibiotics were selected for their variety of action mechanisms, revealing different profiles of resistance for the strains similar to the results of Schirru et al. [43]. The different enterococcal strains were sensitive to vancomycin, while Chahad et al. [42] and Haghshenas et al. [46] reported that all tested enterococci were resistant to vancomycin; they claimed that this resistance is an intrinsic property for most LAB. The isolated L. plantarum EyLan2 was sensitive to penicillin G, chloramphenicol, gentamicin, and clindamycin in agreement with the results of Haghshenas et al. [46]. However, the presence of antibiotic resistance properties among probiotic 
bacteria is advantageous as this allows the bacteria to survive in the gastrointestinal tract during antibiotic treatment. In our study, lactobacilli and all other strains were sensitive to aminoglycosides, represented by gentamicin, while very few were resistant to clindamycin. Among streptococci, 100\% were sensitive to gentamicin and chloramphenicol, while Federici et al. [11] reported that $16.67 \%$ of LAB isolates were resistant to clindamycin and $69.23 \%$ and $15.38 \%$ of lactobacilli were resistant to gentamicin and clindamycin, respectively, and $75 \%$ and $75 \%$ of streptococci exhibited resistance to gentamicin and chloramphenicol, respectively.

The absence of cytolysin coding genes is a good characteristic in the food applications of enterococci and other LAB. Cytolysin is a bacterial toxin expressed by some isolates of E. faecalis which displays both hemolytic and bactericidal activities [51]. All the 46 studied strains exhibited no $\beta$ hemolytic activity, which is in agreement with Chahad et al. [42] and Bozoudi et al. [8]. This characteristic confirms that these $\mathrm{LAB}$ can be used safely in food applications. The ability of the isolated LAB strains to resist acid and bile is an important probiotic property, since they have to survive the conditions in the stomach and the small intestine $[53,54]$. The 46 strains identified in the present study differentially tolerate the acidic and bile conditions; $59 \%$ of the isolated LAB were tolerant at a high rate. Washington et al. [3] also indicated that $72 \%$ of the tested LAB are tolerant to acidity and bile at a survival rate of $90 \%$, while Messaoudi et al. [53] reported that the L. salivarius SMXD51 can tolerate gastrointestinal conditions ( $\mathrm{pH} 3$ acidity and $0.5 \% \mathrm{w} / \mathrm{v}$ bile) with a $99 \%$ rate of survival. In our study, the behavior of most lactobacilli, especially the strains L. casei MSJ1, L. casei BgShn3, and L. Casei Dwan5, was similar to that observed by Messaoudi et al. [53]. Ladda et al. [55] indicated that $L$. paracasei, L. casei, and W. confusa were tolerant to acidity and bile at pH 3.0 and 4\% bile, respectively. Bujnakova et al. [33] indicated that L. salivarius, L. agilis, L. reuteri, L. murinus, and $L$. amylovorus were tolerant to acidity and bile at $\mathrm{pH}$ 2.5 and $0.3 \%$ bile, respectively. The strains of $L$. paracase $i, L$. casei, and Lactobacillus rhamnosus isolated by Reale et al. [2] exhibited high acidity and bile tolerance at $\mathrm{pH} 3.5$ and $1.5 \%$ bile, respectively. However, Ahmadova et al. [51] reported that E. faecium AQ71 could not grow at $\mathrm{pH} 3$ and 4, while it can grow in the presence of bile concentrations ranging from $0.2 \%$ to $0.3 \%$.

As for the antibacterial activity, the largest antimicrobial spectrum in the present study was exerted by CFS of Lactobacillus casei MSJ1, Lactobacillus casei MasaLam7, Lactobacillus casei Dwan5, Enterococcus faecium BawZir8, Lactobacillus paracasei NMBM1, Lactobacillus casei BgShn3, and Lactobacillus plantarum EyLan2, as they inhibited all the indicator strains. The indicator strain E. coli ATCC 25922 in the present study was sensitive to as many as 38 LAB strains. The LAB isolates studied by Bozoudi et al. [8] almost inhibited the growth of E. faecalis, E. coli (100\%), S. aureus, and L. monocytogenes. In our study, no inhibition was observed by the isolated E. faecalis Shbam40 against E. faecalis (ATCC 29212).

Our results indicated that the tested Gram-positive indicator bacteria were more sensitive to the antimicrobial activity of LAB to some extent than the Gram-negative ones, which agrees partially with the results of Ghanbari et al. [56]. Washington et al. [3] indicated no clear relationship between the Gram type of indicator bacteria and their sensitivity to LAB. They also stated that the number of isolated LAB inhibiting the growth of L. monocytogenes (ATCC 7644) was greater than the number of those inhibiting E. faecalis (ATCC 19433), E. coli (ATCC 8739), Salmonella Typhi (ATCC 6539), Shigella flexneri (ATCC 12022), and S. aureus (ATCC 25923). On the other hand, Strompfova and Laukova [24] showed that the growth of all tested Gram-negative indicators was highly inhibited by LAB compared to the inhibition of Grampositive indicators.

\section{Conclusions}

The raw and fermented milk of animals from Saudi Arabia, especially stirred yogurt (Laban) made from camel milk, was confirmed to be rich in LAB. The most important strains with promising probiotic potential for beneficial applications are Lactobacillus casei MSJ1, Lactobacillus casei Dwan5, Lactobacillus plantarum EyLan2, and Enterococcus faecium GailBawZir8. We argue that studying the synergistic effects of bacterial combinations might result in the occurrence of a more effective probiotic potential.

\section{Conflicts of Interest}

The authors declare that there are no conflicts of interest.

\section{Acknowledgments}

The authors would like to acknowledge Faculty of Science, King Abdulaziz University, Jeddah, Saudi Arabia, for their technical and financial support.

\section{References}

[1] FAO/WHO, Joint FAO/WHO Working Group Report on Drafting Guidelines for the Evaluation of Probiotics in Food London, FAO/WHO, Ontario, Canada, 2002.

[2] A. Reale, T. Di Renzo, F. Rossi et al., "Tolerance of Lactobacillus casei, Lactobacillus paracasei and Lactobacillus rhamnosus strains to stress factors encountered in food processing and in the gastro-intestinal tract," LWT-Food Science and Technology, vol. 60, no. 2, pp. 721-728, 2015.

[3] W. L. G. de Almeida Júnior, Í. D. S. Ferrari, J. V. de Souza, C. D. A. da Silva, M. M. da Costa, and F. S. Dias, "Characterization and evaluation of lactic acid bacteria isolated from goat milk," Food Control, vol. 53, pp. 96-103, 2015.

[4] S. D. Todorov and B. D. G. de Melo Franco, "Lactobacillus plantarum: Characterization of the species and application in food production," Food Reviews International, vol. 26, no. 3, pp. 205-229, 2010.

[5] L. Tserovska, S. Stefanova, and T. Yordanova, "Identification of lactic acid bacteria isolated from Katyk, goats milk and cheese," Journal of Culture Collections, vol. 3, pp. 48-52, 2002.

[6] L. M. Cintas, M. P. Casaus, C. Herranz, I. F. Nes, and P. E. Hernández, "Review: Bacteriocins of Lactic Acid Bacteria," 
Food Science and Technology International, vol. 7, no. 4, pp. 281305, 2001.

[7] X. Lü, L. Yi, J. Dang, Y. Dang, and B. Liu, "Purification of novel bacteriocin produced by Lactobacillus coryniformis MXJ 32 for inhibiting bacterial foodborne pathogens including antibioticresistant microorganisms," Food Control, vol. 46, pp. 264-271, 2014.

[8] D. Bozoudi, C. Kotzamanidis, M. Hatzikamari, N. Tzanetakis, G. Menexes, and E. Litopoulou-Tzanetaki, "A comparison for acid production, proteolysis, autolysis and inhibitory properties of lactic acid bacteria from fresh and mature Feta PDO Greek cheese, made at three different mountainous areas," International Journal of Food Microbiology, vol. 200, pp. 87-96, 2015.

[9] G. Tabanelli, C. Montanari, E. Bargossi et al., "Control of tyramine and histamine accumulation by lactic acid bacteria using bacteriocin forming lactococci," International Journal of Food Microbiology, vol. 190, pp. 14-23, 2014.

[10] M. Palomo, A. M. Gutiérrez, M. C. Pérez-Conde, C. Cámara, and Y. Madrid, "Se metallomics during lactic fermentation of Se-enriched yogurt," Food Chemistry, vol. 164, pp. 371-379, 2014.

[11] S. Federici, F. Ciarrocchi, R. Campana, E. Ciandrini, G. Blasi, and W. Baffone, "Identification and functional traits of lactic acid bacteria isolated from Ciauscolo salami produced in Central Italy," Meat Science, vol. 98, no. 4, pp. 575-584, 2014.

[12] K. Henríquez-Aedo, D. Durán, A. Garcia, M. B. Hengst, and M. Aranda, "Identification of biogenic amines-producing lactic acid bacteria isolated from spontaneous malolactic fermentation of chilean red wines," LWT- Food Science and Technology, vol. 68, pp. 183-189, 2016.

[13] L. A. Nero, M. R. De Mattos, M. De Aguiar Ferreira Barros, M. B. T. Ortolani, V. Beloti, and B. D. G. De Melo Franco, "Listeria monocytogenes and Salmonella spp. in raw milk produced in Brazil: Occurrence and interference of indigenous microbiota in their isolation and development," Zoonoses and Public Health, vol. 55, no. 6, pp. 299-305, 2008.

[14] L. O'Sullivan, R. P. Ross, and C. Hill, "Potential of bacteriocinproducing lactic acid bacteria for improvements in food safety and quality," Biochimie, vol. 84, no. 5-6, pp. 593-604, 2002.

[15] K. Angmo, A. Kumari, Savitri, and T. C. Bhalla, "Probiotic characterization of lactic acid bacteria isolated from fermented foods and beverage of Ladakh," LWT- Food Science and Technology, vol. 66, pp. 428-435, 2016.

[16] T. K. A. Bezerra, N. M. D. O. Arcanjo, A. R. R. D. Araújo et al., "Volatile profile in goat coalho cheese supplemented with probiotic lactic acid bacteria," LWT- Food Science and Technology, vol. 76, pp. 209-215, 2017.

[17] A. Kumar and D. Kumar, "Characterization of Lactobacillus isolated from dairy samples for probiotic properties," Anaerobe, vol. 33, pp. 117-123, 2015.

[18] P. Li, H. Luo, B. Kong, Q. Liu, and C. Chen, "Formation of red myoglobin derivatives and inhibition of spoilage bacteria in raw meat batters by lactic acid bacteria and Staphylococcus xylosus," LWT- Food Science and Technology, vol. 68, pp. 251-257, 2016.

[19] Y. Sha, L. Wang, M. Liu, K. Jiang, F. Xin, and B. Wang, "Effects of lactic acid bacteria and the corresponding supernatant on the survival, growth performance, immune response and disease resistance of Litopenaeus vannamei," Aquaculture, vol. 452, pp. 28-36, 2016.

[20] M. T. Liong and N. P. Shah, "Bile salt deconjugation ability, bile salt hydrolase activity and cholesterol co-precipitation ability of lactobacilli strains," International Dairy Journal, vol. 15, no. 4, pp. 391-398, 2005.
[21] A. C. Ouwehand, S. Salminen, and E. Isolauri, "Probiotics: an overview of beneficial effects," Antonie van LeeuwenhoekJournal of Microbiology, vol. 82, no. 1-4, pp. 279-289, 2002.

[22] G. Giraffa, "Functionality of enterococci in dairy products," International Journal of Food Microbiology, vol. 88, no. 2-3, pp. 215-222, 2003.

[23] A. Mercenier, S. Pavan, and B. Pot, "Probiotics as biotherapeutic agents: Present knowledge and future prospects," Current Pharmaceutical Design, vol. 9, no. 2, pp. 175-191, 2003.

[24] V. Strompfová and A. Lauková, "Isolation and characterization of faecal bifidobacteria and lactobacilli isolated from dogs and primates," Anaerobe, vol. 29, pp. 108-112, 2014.

[25] M. Kargozari, Z. Emam-Djomeh, H. Gandomi, R. Partovi, M. Ghasemlou, and I. R. Martin, "Identification of selected Lactobacillus strains isolated from Siahmazgi cheese and study on their behavior after inoculation in fermented-sausage model medium," LWT- Food Science and Technology, vol. 62, no. 2, pp. 1177-1183, 2015.

[26] M. Nacef, M. Chevalier, S. Chollet, D. Drider, and C. Flahaut, "MALDI-TOF mass spectrometry for the identification of lactic acid bacteria isolated from a French cheese: The Maroilles," International Journal of Food Microbiology, vol. 247, pp. 2-8, 2017.

[27] S. Singh, P. Goswami, R. Singh, and K. J. Heller, "Application of molecular identification tools for Lactobacillus, with a focus on discrimination between closely related species: A review," LWTFood Science and Technology, vol. 42, no. 2, pp. 448-457, 2009.

[28] m. Tärnberg, t. Jakobsson, j. Jonasson, and u. Forsum, "Identification of randomly selected colonies of lactobacilli from normal vaginal fluid by pyrosequencing of the $16 \mathrm{~S}$ rDNA variable V1 and V3 regions," APMIS-Acta Pathologica, Microbiologica et Immunologica Scandinavica, vol. 110, no. 11, pp. 802-810, 2002.

[29] J. Yang, Y. Ji, H. Park et al., "Selection of functional lactic acid bacteria as starter cultures for the fermentation of Korean leek (Allium tuberosum Rottler ex Sprengel.)," International Journal of Food Microbiology, vol. 191, pp. 164-171, 2014.

[30] M. Carmen Collado and M. Hernández, "Identification and differentiation of Lactobacillus, Streptococcus and Bifidobacterium species in fermented milk products with bifidobacteria," Microbiological Research, vol. 162, no. 1, pp. 86-92, 2007.

[31] A. M. O. Leite, M. A. L. Miguel, R. S. Peixoto et al., "Probiotic potential of selected lactic acid bacteria strains isolated from Brazilian kefir grains," Journal of Dairy Science, vol. 98, no. 6, pp. 3622-3632, 2015.

[32] M. M. M. Ahmed, E. E. Hafez, M. A. Mkamer, H. A.-A. ElAbdelrrassoul, and Y. M. A. Mabrouk, "Application of DNA technology to detect food infection with some pathogenic bacteria using 16S rDNA gene, PCR-RFLP and sequencing," Journal of Food, Agriculture and Environment (JFAE), vol. 12, no. 2, pp. 202-206, 2014.

[33] D. Bujnakova, E. Strakova, and V. Kmet, "Invitro evaluation of the safety and probiotic properties of Lactobacilli isolated from chicken and calves," Anaerobe, vol. 29, pp. 118-127, 2014.

[34] R. Fuller, "Probiotics in man and animals," Journal of Applied Bacteriology, vol. 66, no. 5, pp. 365-378, 1989.

[35] J. C. de Man, M. Rogosa, and M. E. Sharpe, "A medium for the cultivation of Lactobacilli," Journal of Applied Bacteriology, vol. 23, no. 1, pp. 130-135, 1960.

[36] R. R. Ravula and N. P. Shah, "Selective enumeration of Lactobacillus casei from yogurts and fermented milk drinks," Biotechnology Techniques, vol. 12, no. 11, pp. 819-822, 1998. 
[37] B. E. Terzaghi and W. E. Sandine, "Improved medium for lactic streptococci and their bacteriophages," Journal of Applied Microbiology, vol. 29, no. 6, pp. 807-813, 1975.

[38] S. Macwana and P. M. Muriana, "Spontaneous bacteriocin resistance in Listeria monocytogenes as a susceptibility screen for identifying different mechanisms of resistance and modes of action by bacteriocins of lactic acid bacteria," Journal of Microbiological Methods, vol. 88, no. 1, pp. 7-13, 2012.

[39] I. Javed, Characterization of bacteriocin produced by lactic acid bacteria isolated from dairy products [Ph.D. thesis], Quaid-iAzam University, Islamabad, Pakistan, 2009.

[40] Y. Sun, X. Lou, X. Zhu, H. Jiang, and Q. Gu, "Isolation and characterization of lactic acid bacteria producing bacteriocin from newborn infants feces," Journal of Bacteriology and Mycology, vol. 1, no. 2, pp. 1-7, 2014.

[41] M. Bosch, J. Nart, S. Audivert et al., "Isolation and characterization of probiotic strains for improving oral health," Archives of Oral Biolog, vol. 57, no. 5, pp. 539-549, 2012.

[42] O. B. Chahad, M. El Bour, P. Calo-Mata, A. Boudabous, and J. Barros-Velàzquez, "Discovery of novel biopreservation agents with inhibitory effects on growth of food-borne pathogens and their application to seafood products," Research in Microbiology, vol. 163, no. 1, pp. 44-54, 2012.

[43] S. Schirru, S. D. Todorov, L. Favaro et al., "Sardinian goat's milk as source of bacteriocinogenic potential protective cultures," Food Control, vol. 25, no. 1, pp. 309-320, 2012.

[44] S. V. Hosseini, S. Arlindo, K. Böhme, C. Fernández-No, P. CaloMata, and J. Barros-Velázquez, "Molecular and probiotic characterization of bacteriocin-producing Enterococcus faecium strains isolated from nonfermented animal foods," Journal of Applied Microbiology, vol. 107, no. 4, pp. 1392-1403, 2009.

[45] Y. A. Chabbert, "Lantibiogramme," in Bacteriologie Medicale, L. Le Miror and M. Veron, Eds., pp. 205-212, Medecine Science, Paris, France, 1982.

[46] B. Haghshenas, N. Abdullah, Y. Nami, D. Radiah, R. Rosli, and A. Y. Khosroushahi, "Different effects of two newly-isolated probiotic Lactobacillus plantarum $15 \mathrm{HN}$ and Lactococcus lactis subsp. Lactis 44Lac strains from traditional dairy products on cancer cell lines," Anaerobe, vol. 30, pp. 51-59, 2014.

[47] R. C. Anderson, A. L. Cookson, W. C. McNabb, W. J. Kelly, and N. C. Roy, "Lactobacillus plantarum DSM 2648 is a potential probiotic that enhances intestinal barrier function," FEMS Microbiology Letters, vol. 309, no. 2, pp. 184-192, 2010.

[48] F. Ait Ouali, I. Al Kassaa, B. Cudennec et al., "Identification of lactobacilli with inhibitory effect on biofilm formation by pathogenic bacteria on stainless steel surfaces," International Journal of Food Microbiology, vol. 191, pp. 116-124, 2014.

[49] J. L. Balcázar, I. de Blas, I. Ruiz-Zarzuela, D. Vendrell, O. Gironés, and J. L. Muzquiz, "Sequencing of variable regions of the 16S rRNA gene for identification of lactic acid bacteria isolated from the intestinal microbiota of healthy salmonids," Comparative Immunology, Microbiology \& Infectious Diseases, vol. 30, no. 2, pp. 111-118, 2007.

[50] S. Chakravorty, S. Sarkar, and R. Gachhui, "Identification of new conserved and variable regions in the 16S rRNA gene of acetic acid bacteria and acetobacteraceae family," Journal of Molecular Biology, vol. 49, no. 5, pp. 668-677, 2015.

[51] A. Ahmadova, S. D. Todorov, Y. Choiset et al., "Evaluation of antimicrobial activity, probiotic properties and safety of wild strain Enterococcus faecium AQ71 isolated from Azerbaijani Motal cheese," Food Control, vol. 30, no. 2, pp. 631-641, 2013.
[52] S. Mathur and R. Singh, "Antibiotic resistance in food lactic acid bacteria-a review," International Journal of Food Microbiology, vol. 105, no. 3, pp. 281-295, 2005.

[53] S. Messaoudi, A. Madi, H. Prévost et al., "In vitro evaluation of the probiotic potential of Lactobacillus salivarius SMXD51," Anaerobe, vol. 18, no. 6, pp. 584-589, 2012.

[54] B. A. Neville and P. Otoole, "Probiotic properties of Lactobacillus salivarius and closely related ctobacillus species," Future Microbiology, vol. 5, no. 5, pp. 759-774, 2010.

[55] B. Ladda, T. Theparee, J. Chimchang, S. Tanasupawat, and M. Taweechotipatr, "In vitro modulation of tumor necrosis factor $\alpha$ production in THP-1 cells by lactic acid bacteria isolated from healthy human infants," Anaerobe, vol. 33, pp. 109-116, 2015.

[56] M. Ghanbari, M. Jami, W. Kneifel, and K. J. Domig, "Antimicrobial activity and partial characterization of bacteriocins produced by lactobacilli isolated from Sturgeon fish," Food Control, vol. 32, no. 2, pp. 379-385, 2013. 


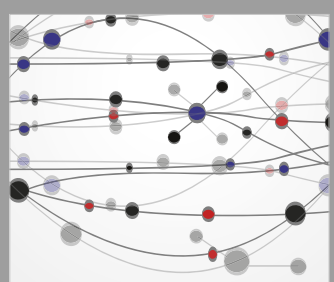

The Scientific World Journal
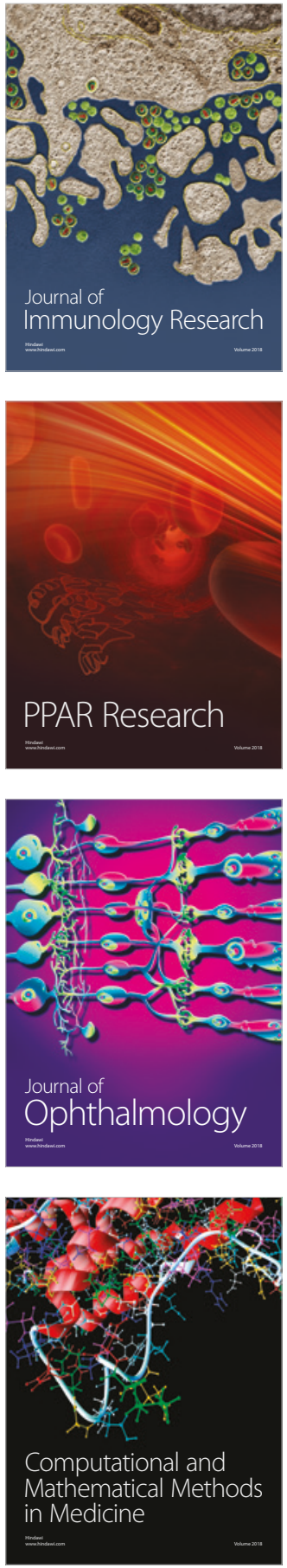

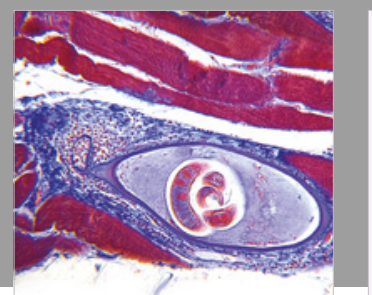

Gastroenterology Research and Practice

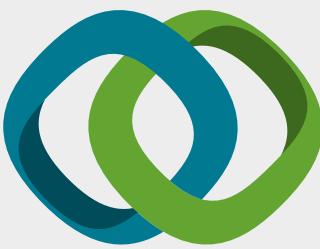

\section{Hindawi}

Submit your manuscripts at

www.hindawi.com
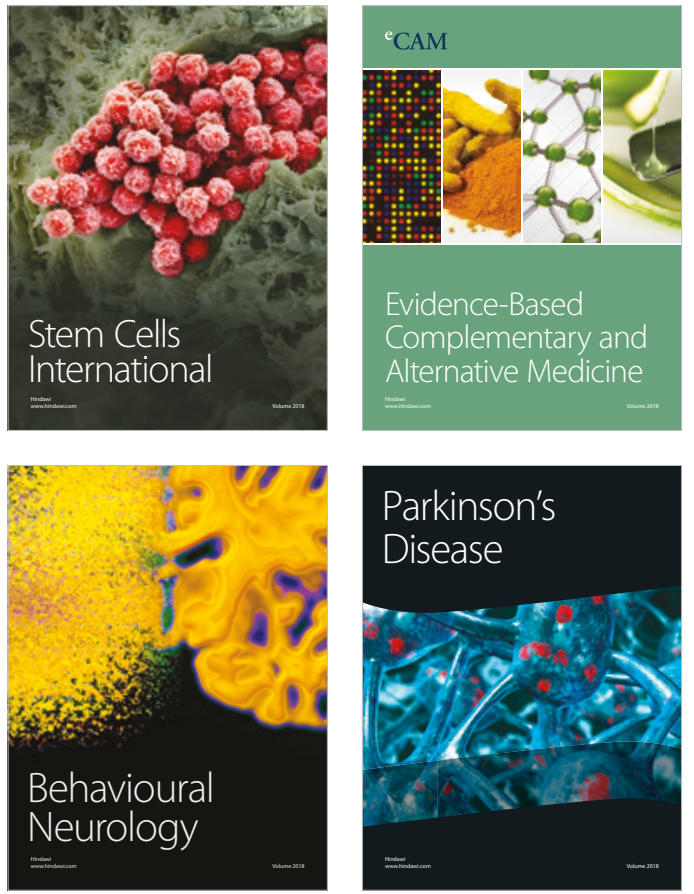

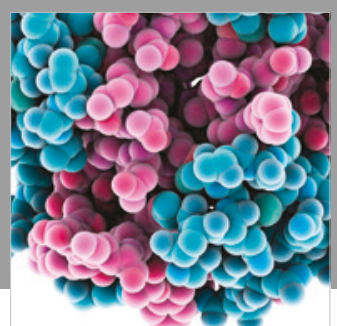

ournal of

Diabetes Research

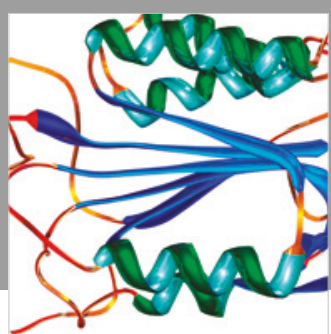

Disease Markers
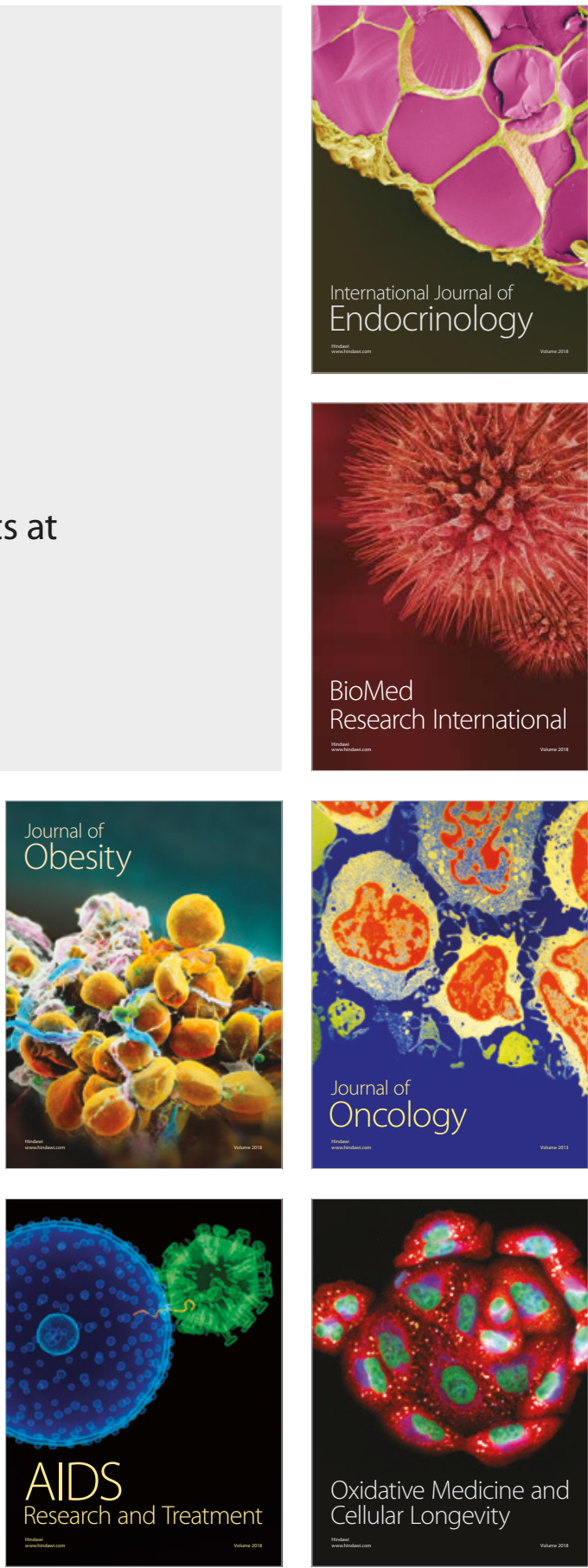